\title{
MicroG Buenos Aires is born: Space and Applied Neuroscience Lab joins the MicroG Labs Network
}

\section{Nasce o MicroG Buenos Aires: Laboratório de Neurociência especial e aplicada une-se com o MicroG Labs Network}

\author{
Daniel Eduardo Vigo 1,3, Rafael Reimann Baptista ${ }^{2,3}$, Thais Russomano, \\ Space and Applied Neuroscience Laboratory, Institute for Biomedical Research (BIOMED), School of Medical Sciences, Pontifical Catholic University of Argentina (UCA), \\ and the National Scientific and Technical Research Council (CONICET), Buenos Aires, Argentina. \\ ${ }^{2}$ Microgravity Centre, PUCRS, Porto Alegre, Brazil \\ MicroG Labs Network.
}

\begin{abstract}
E dition number 2, volume 5, 2014 of Aviation in Focus - Journal of Aeronautical Sciences brings together four interesting articles, like that entitled "Man-machine interaction in technologically advanced aircraft: transformation of a paradigm". Based on a literature review, this paper presents a discussion of the transformation of aircraft management processes, characterized by the increasing automation of aviation and reflecting on the man-machine interaction in technologically advanced aircraft (TAA).

The new edition also includes two interesting contributions from the Brazilian Air Force. The first article, "Analysis of the forces exerted in flight by Aviator Cadets of the Brazilian Air Force", presents an evaluation of muscular force of aviator cadets submitted to a training program in an Aircraft Force Simulator, prototype EMB312/T-27. The second article, "The influence of airsickness on learning and flight instruction of aviator cadets of the Brazilian Air Force", investigates the prevalence of airsickness among aviator cadets of the Brazilian Air Force, based in Pirassununga, São Paulo state, their search for medical treatment and the influence of symptoms on their performance.

The fourth paper in this issue, "The relationship between institutions, human factors and operational safety in aviation" examines the relationship between the organization and the individual, in other words, the role of organizational culture on the implementation of human factors in the daily operations of an airline company, and the influence this process has on the level of operational safety.
\end{abstract}

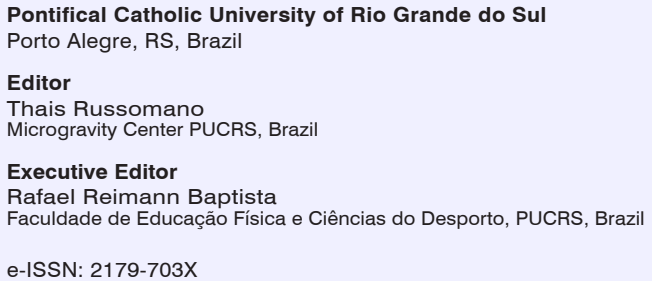

Corresponding Author:

Thais Russomano

trussomano@hotmail.com

Received: December 20, 2014 Accepted: December 20, 2014

(C) 2014 EDIPUCRS 
The current Editorial also includes a special guest, Prof. Daniel Vigo from the Space and Applied Neuroscience Laboratory (SPAN Lab) in Buenos Aires, Argentina, for the announcement of the launch of the MicroG Lab Buenos Aires, the latest addition to the MicroG Labs Network.

The SPAN Lab traces its origins back to the Neuroscience Laboratory of the University of Buenos Aires, where Argentine scientist Daniel Cardinali conducted a 50-year pioneering work in the field of sleep physiology (1). Studies in space life science research in this new lab began following a cooperation established in 2010 with the Katholieke Universiteit Leuven, Belgium, which enabled participation in the Mars500 project (Russian Academy of Sciences, European Space Agency). In the study connected to that project, autonomic profiles associated with prolonged confinement were described (2-4). In 2012, the "First International Workshop on Human Space Physiology" (http://www.spacelife.com.ar) was held in Argentina, where local and international scientists from Brazil (MicroG-PUCRS) and Europe (DLR, Katholieke Universiteit Leuven) exchanged views regarding possible cooperation opportunities at national and international levels. In 2013, the study "Chronobiology of Antarctic Isolation: the use of Belgrano II Antarctic Station as a Space Analogue" was launched in collaboration with Quilmes National University, the Argentine Army, National Antarctic Direction, and several European laboratories.

The MicroG Labs network is an entrepreneurial initiative that aims to establish an international consortium formed of different research laboratories related to space sciences. The purpose is to create common ground for the creation of research projects, to stimulate academic mobility and help develop educational activities, especially in an e-learning format.

Talks regarding the establishment of the MicroG Lab Buenos Aires within the Space and Applied Neuroscience Laboratory started in 2014, following a proposal from the Head of the MicroG Centre-PUCRS, Prof. Thais Russomano. The creation of an international network facilitates the common use of human and material resources to increase activity in the areas of scientific research, postgraduate education and outreach services. In addition, the foundation of an international network will increase the opportunities for obtaining funding grants.

Current plans for the MicroG Lab Buenos Aires and MicroG-PUCRS partnership include the design of a joint project to examine how sleep deprivation affects the biomechanical response to simulated microgravity exposure; devising postgraduate courses to be delivered in 2015; and planning the $2^{\text {nd }}$ International Workshop on Human Space Physiology.

\section{References}

1. Cardinali DP. Cincuenta Años con la Piedra de la Locura. Apuntes Autobiográficos de un Científico Argentino. Buenos Aires: Edición del autor; 2014.

2. Vigo DE, Ogrinz B, Wan L, Bersenev E, Tuerlinckx F, Van den Bergh O, et al. Sleep-wake differences in heart rate variability during a 105-day simulated mission to Mars. Aviat Space Environ Med 2012 Feb.; 83(2): $125-30$.

3. Vigo DE, Tuerlinckx F, Ogrinz B, Wan L, Simonelli G, Bersenev E, et al. Circadian rhythm of autonomic cardiovascular control during Mars500 simulated mission to Mars. Aviat Space Environ Med 2013 Oct.; $84(10): 1023-8$.

4. Wan L, Ogrinz B, Vigo D, Bersenev E, Tuerlinckx F, Van den Bergh O, et al. Cardiovascular autonomic adaptation to long-term confinement during a 105-day simulated Mars mission. Aviat Space Environ Med 2011 July; 82(7):711-6. 